УДК 351.778

DOI: $10.26435 /$ UC.V0I2(35).507

\author{
Е.А. Шумаева ${ }^{1}$, О.В. Гура ${ }^{2}$ \\ ${ }^{1}$ ГОУ ВПО «Донецкий национальный технический университет», Донецк \\ 2Республиканская служба лекарственных средств МЗ ДНР
}

\title{
АНАЛИЗ ГОСУДАРСТВЕННОЙ ПОЛИТИКИ КОНТРОЛЯ ЗА ОБОРОТОМ ЛЕКАРСТВЕННЫХ СРЕДСТВ В РОССИЙСКОЙ ФЕДЕРАЦИИ
}

\begin{abstract}
Эффективная система здравоохранения в любом обществе является важным элементом функционирования государства наравне со справедливой системой правосудия и демократической политической системой. Тем не менее несовершенство государственной политики регулирования сектора здравоохранения, особенно оборота лекарственных средств, во многих странах, в том числе и в Российской Федерации, ведет к обширным нарушениям прав человека. В силу особого отношения государства к охране здоровья населения сфера обращения лекарственных средств имеет огромную социальную значимость, которая выражается в возведении права на доступное и качественное медицинское обеспечение в ранг конституционных. Поэтому эта сфера ни в коем случае не должна оставаться без пристального и постоянного внимания, а также жесткого контроля со стороны государства. На сегодняшний день одной из наиболее актуальных проблем мирового уровня является борьба с незаконным оборотом и фальсификацией лекарственных средств.
\end{abstract}

\section{ЦЕЛ Ь РАБОТЫ}

Проанализировать государственную политику контроля за оборотом лекарственных средств в Российской Федерации и выявить предпосылки к возникновению нарушений в обороте лекарственных средств.

Изучению вопросов государственной политики за контролем оборота лекарственных средств посвящены труды таких авторов, как Е.В. Евсикова, Н.Г. Денисова, Ю.Н. Аксенова-Сорохтей, Т.А. Антонова, Е.А. Барановская, И.А. Булахова, А.А. Митюнова, В.С. Маличенко, Р.У. Хабриев, А.Х. Абашидзе. В частности, Ю.Н. АксеноваСорохтей и Е.А. Барановская особое внимание уделяют исследованию правовых проблем организации эффективного контроля в сфере обращения лекарственных средств. В. С. Маличенко, А. Х. Абашидзе в своих трудах анализируют роль развития системы регулирования оборота лекарственных средств в реализации права человека на наивысший достижимый уровень здоровья. Основными методами обработки информации, которые использованы в статье, являются методы синтеза и анализа, методы группировки, сравнения.

Теорией доказана и практикой всех развитых стран подтверждена необходимость активного участия современного государства в регулировании отношений, возникающих на фармацевтическом рынке, его мониторинге и организации контроля. Несмотря на сохраняющуюся дискуссионность вопроса о методах и принципах этого регулирования, степени вмешательства органов государственной власти в функционирование фармацевтического рынка, общепризнанно, что государственное регулирование оборота лекарственных средств предполагает выработку эффективной государственной политики и создание системы нормативноправового обеспечения вопросов регулирования в сфере обращения лекарственных средств [1, с. 216]. Суть государственной политики в сфере обращения лекарственных средств должна выражаться в реализации различных функций, которые выявляются после обозначения и исследования актуальных проблем законодательства в качестве необходимых мер для их решения: надлежащая подготовка и переподготовка кадров, рациональное финансирование программ социального обеспечения, финансирование научных исследований, внедрение инноваций в отрасли, осуществление контроля за оборотом лекарственных средств.

Оборот лекарственных средств (далее - ЛС) представляет собой достаточно сложную систему, структурные элементы которой находятся в непрерывном взаимодействии с различными сферами человеческой деятельно-

(C) Е.А. Шумаева, О.В. Гура, 2020

(c) Университетская Клиника, 2020 
сти. Многие аспекты глобализации (нарастающая экономическая нестабильность, социальнодемографические процессы, непропорциональный доступ к лекарственному обеспечению) предъявляют серьезные требования к управлению системой здравоохранения, особенно в части контроля оборота лекарственных средств. Доминирующей статьей затрат системы здравоохранения являются затраты на лекарственную помощь. Рациональное применение и обеспечение доступа ЛС оказывают прямое влияние на снижение экономического бремени от многих заболеваний, способствуют снижению общих расходов на медицинскую помощь [2, с. 17].

Российская Федерация с 1998 г. является официальным участником международной программы Всемирной организации здравоохранения по мониторингу безопасности ЛС. В Российской Федерации стратегической целью государственной политики оборота лекарственных средств является совершенствование системы безопасности, контроля эффективности и качества ЛС, их гарантированная доступность для граждан.

Законодательство в сфере обращения лекарственных средств развивается достаточно динамично. Базовый нормативно-правовой акт, peгулирующий отношения в данной области, Федеральный закон «Об обращении лекарственных средств» от 12.04.2010 г. № 61-Ф3 (в ред. от 27.12.2018), является вторым с момента начала политических и экономических преобразований 1990-х гг. В 2014 г. закон подвергся масштабным изменениям. К основным можно отнести:

- существенное обновление понятийного аппарата;

- корректировка процедуры регистрации лекарственных препаратов: в целом она облегчена (от нее отделены клинические исследования) и стала более прозрачной;

- введение новой формы государственного контроля в данной сфере - фармаконадзор;

- закрепление процедуры выборочного контроля лекарственных средств.

Согласно действующему законодательству Российской Федерации, лекарственные средства - это вещества или их комбинации, которые вступают в контакт с организмом человека или животного и применяются для профилактики, диагностики, лечения заболевания, реабилитации, для сохранения, предотвращения или прерывания беременности.

Под обращением лекарственных средств понимаются все этапы их жизненного цикла, начиная от разработки, проведения доклинических и клинических исследований, государственной регистрации и т.д., заканчивая хранением, peaлизацией, уничтожением [3].

Федеральный государственный контрольоборота лекарственных средств в Российской Федерации в соответствии со статьей 9 Федерального закона от 12.04.2010 г. № 61-Ф3 «Об обращении лекарственных средств» осуществляется Федеральной службой по надзору в сфере здравоохранения (далее - Росздравнадзор) посредством:

1) организации и проведения фармаконадзоpa;

2) организации и проведения проверок субъектов, участвующих в обороте ЛС, на предмет соблюдения ими требований к доклиническим исследованиям лекарственных средств, клиническим исследованиям лекарственных препаратов, хранению, перевозке, ввозу в Российскую Федерацию, отпуску, реализации лекарственных средств, применению лекарственных препаратов, уничтожению лекарственных средств;

3) организации и проведения проверок соответствия лекарственных средств, находящихся в гражданском обороте, требованиям к их качеству;

4) применения в законодательном порядке мер по пресечению выявленных нарушений обязательных требований и (или) устранению последствий таких нарушений, выдачи соответствующих предписаний и привлечения к ответственности лиц, совершивших такие нарушения [3].

Лекарственные препараты, находящиеся в обороте в Российской Федерации, подлежат мониторингу безопасности и эффективности или фармаконадзору. В большинстве стран мира, как и в России, фармаконадзор является основным направлением деятельности регуляторных органов, осуществляющих контроль за оборотом ЛС, которое позволит заложить основу национальных принципов эффективного и безопасного использования лекарственных средств. Эта деятельность, осуществляемая Росздравнадзором, направлена на выявление, оценку и предупреждение нежелательных реакций или любых других возможных проблем, в том числе таких, как появление недоброкачественных, фальсифицированных и контрафактных лекарственных препаратов. Законодательно проводятся четкие смысловые различия между этими понятиями.

Так, недоброкачественным лекарственным средством признается то, которое не соответствует требованиям фармакопейной статьи либо требованиям нормативной документации.

Фальсифицированное лекарственное средство представляет собой ЛС, которое сопровождается ложной информацией о его составе и 
(или) производителе, то есть по сути это подделка, которая в первую очередь предполагает нарушение технологии производства лекарства.

Контрафактное лекарственное средство - это такое ЛС, которое находится в обороте с нарушением гражданского законодательства, например импортные препараты, ввезенные на территорию страны в обход официальных таможенных процедур, а также отечественные препараты, произведенные без предварительного учета, - так называемый «левый» товар.

В случае выявления всех вышеуказанных препаратов они подлежат уничтожению. На сегодняшний день государственная система в Российской Федерации по контролю безопасности ЛС находится на этапе совершенствования системы фармаконадзора путем гармонизации с международными стандартами, разработки мероприятий и правовых актов [4, с. 26].

На рисунке 1 представлена динамика объема фармацевтического рынка и изъятия из обращения количества серий лекарственных средств, качество которых не отвечает установленным требованиям Российской Федерации, за 2011-2018 гг.

На основании данных, представленных на рисунке 1, можно сделать вывод, что объемы фармацевтического рынка Российской Федерации продолжают увеличиваться - с 824 млрд руб. в 2011 г. до 1682 млрд руб. в 2018 г., при этом наибольшее количество ЛС, изъятых из обращения, было в 2016 г. - 1932 серии, а в 2018 г. при наибольшем объеме фармацевтического рынка составило 752 серии, качество которых не отвечает установленным требованиям.

Несмотря на то, что объемы фармацевтического рынка Российской Федерации демонстрируют определенную динамику роста, можно выделить ряд проблем, которые сдерживают его развитие:

- зависимость от импорта лекарственных средств;

- жесткая конкуренция отечественных ЛС с импортными;

- громоздкая система регистрации инновационных отечественных разработок;

- коррупционные риски, прежде всего при государственной закупке ЛС.

Данные проблемы влияют на увеличение цены на лекарственные средства, способствуют развитию криминализации фармацевтического рынка, особенно производству и распространению ЛС, которые не соответствуют установленным требованиям к их качеству.

На рисунке 2 представлена структура изъятых из оборота лекарственных средств в Российской Федерации за 2016-2018 гг.

Исходя из данных, представленных на рисунке 2, можно сделать следующие выводы:

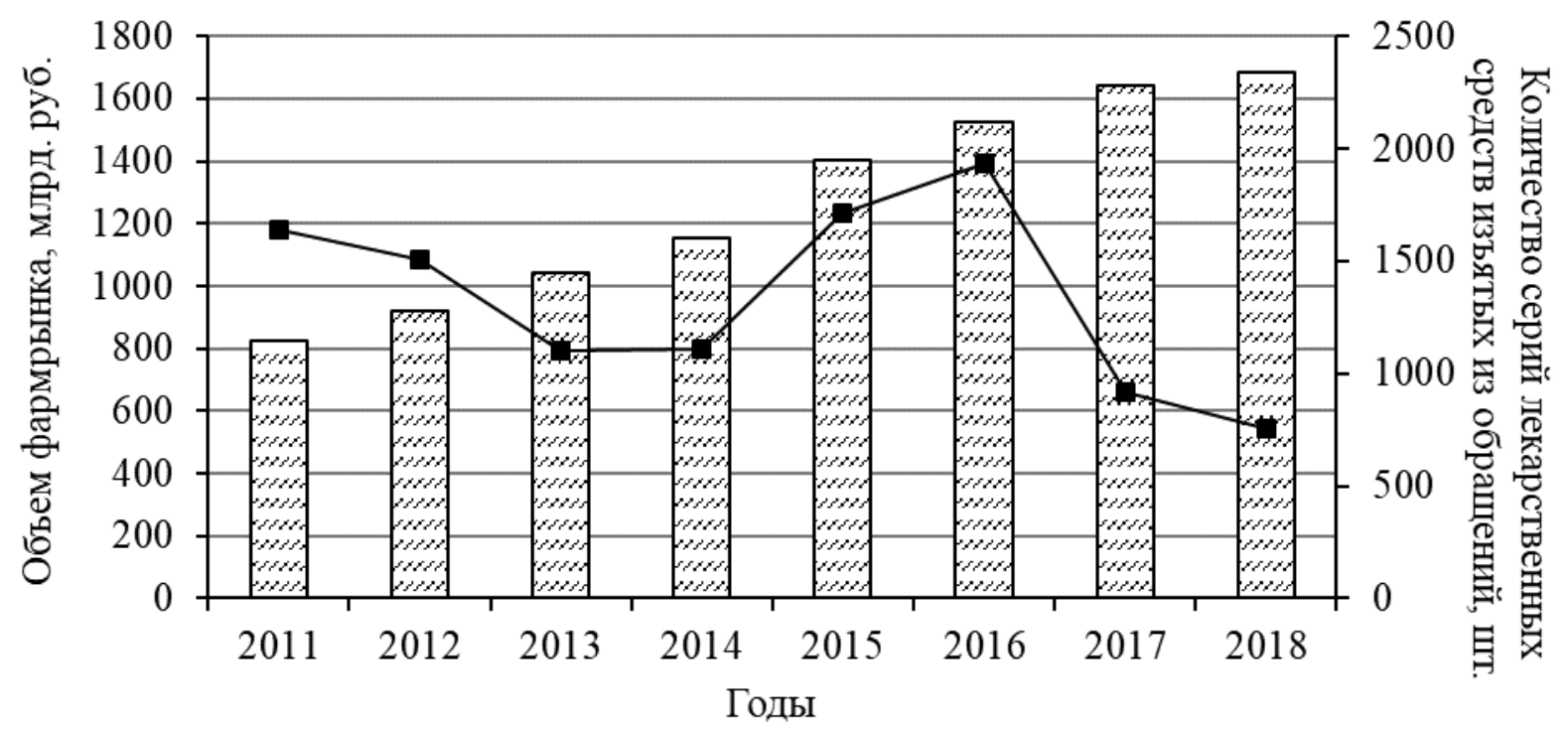

\footnotetext{
жал Динамика объема фармрынка, млрд. руб.

$\rightarrow$-Количество серий лекарственных средств изъятых из обрашения
}

Рис. 1. Динамика объема фармацевтического рынка и изъятия из обращения количество серий лекарственных средств Российской Федерации, 2011 -2018 гг., млрд. руб., шт. (составлено авторами по данным $[5,6])$ 
- в 2016 г. среди лекарственных средств, изъятых из оборота, большую долю (70,43 \%) составляли лекарственные средства, которые были отозваны производителями (импортерами), на втором месте (27,5 \%) - недоброкачественные лекарственные средства;

- в 2017 г. среди лекарственных средств, изъятых из оборота, большую долю (47,43 \%) составляли недоброкачественные лекарственные средства, на втором месте (40,66 \%) - лекарственные средства, которые отозваны производителями (импортерами);

- в 2018 г. среди лекарственных средств, изъятых из оборота, большую долю (58,38 \%) составляли недоброкачественные лекарственные средства, на втором месте (27,79 \%) -лекарственные средства, которые отозваны производителями (импортерами);

- доля фальсифицированных лекарственных средств в 2016 г. составляла 0,57 \%, к 2018 г. увеличилась до 9,84 \%;

- доля контрафактных лекарственных средств в 2016 г. составляла 1,5 \%, в 2018 г. увеличилась до 3,59\%.

Основным нормативно-правовым актом, закрепляющим меры административной ответ- ственности за производство, ввоз и продажу фальсификационных препаратов, является Кодекс об административных правонарушениях Российской Федерации (далее - КоАП РФ), в частности в Главе 14 «Административные правонарушения в области предпринимательской деятельности и деятельности саморегулируемых организаций выделяют следующие статьи»:

- Ст. 14.4.2. Нарушение законодательства об обращении лекарственных средств;

- Ст. 14.4. Нарушение изготовителем, исполнителем (лицом, выполняющим функции иностранного изготовителя), продавцом требований технических регламентов [7].

На рисунке 3 представлена динамика количества проверок, нарушений и сумм наложенных штрафов, выявленных Росздравнадзором в сфере обращения лекарственных средств за 2016-2018 гг.

На основании данных, представленных на рисунке 3, можно сделать вывод, что количество проверок в 2018 г. по сравнению с 2016 г. снизилось на 12\%, однако по сравнению с 2016 г. в 2018 г. количество нарушений законодательства об обращении ЛС выросло в 2 раза. В то же время происходит большее количество нарушений,

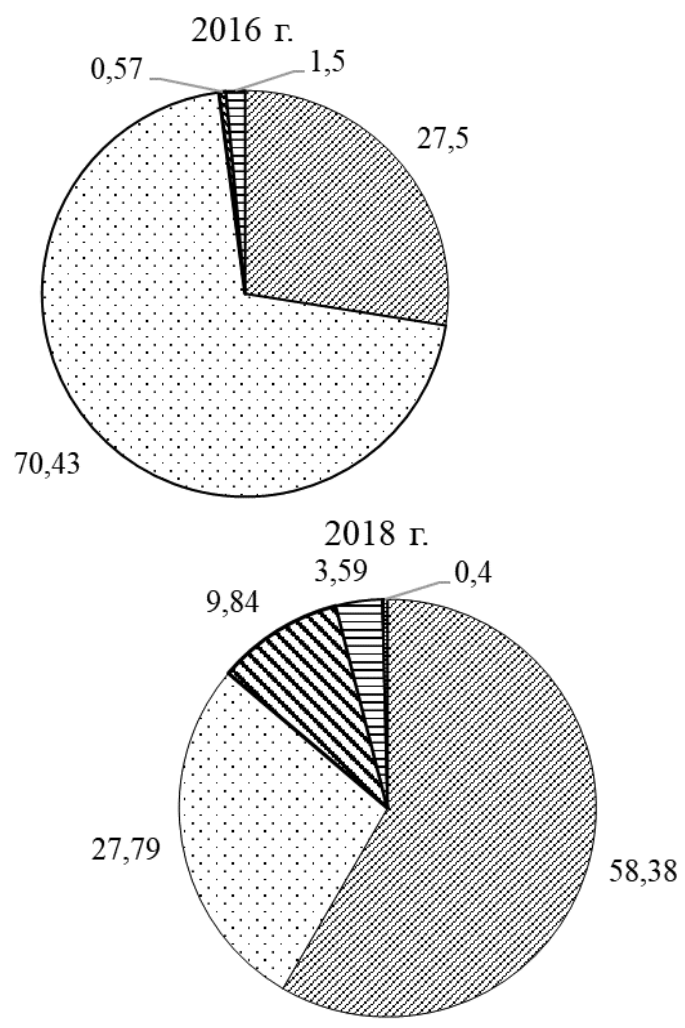

2017 г.

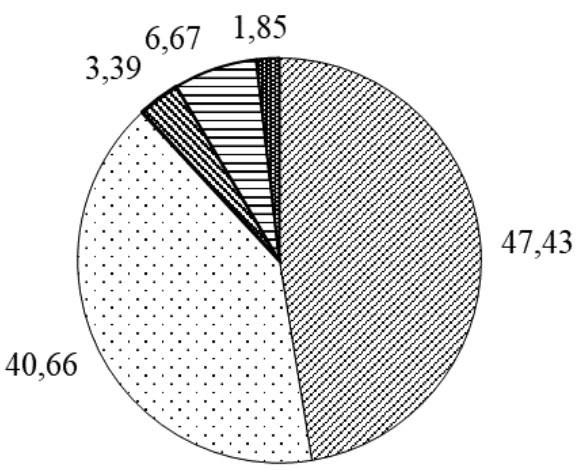

๒ Недоброкачественные лекарственные средства

$\square$ Лекарственные средства, которые отозваны производителями (импортерами)

$\mathbf{\nabla}$ Фальсифицированные препараты

日Контрафактные лекарственные средства

䁬 Незарегистрированные препараты

Рис. 2. Структура изъятых из оборота лекарственных средств в Российской Федерации, 20162018 гг., \% (составлено авторами по данным $[5,6])$ 
которые предусматривают ответственность за несоблюдение правил хранения лекарственных средств, квалифицируемыми может, квалифицируемых? по статье 14.43 КоАП РФ, по сравнению с 2017 г. в 2018 г. их количество выросло до уровня 2016 г.

В 2018 г. назначено административных штрафов по ст. 14.4.2 на сумму 12705,2 тыс. руб., по ст. 14.43 - на сумму 63378,41 тыс. руб., что в 1,5 раза меньше, чем в 2017 г. При этом средняя сумма одного административного штрафа в 2018 г. составила 23,43 тыс. руб. (в 2017 г. - 46,98 тыс. руб., в 2016 г. - 41,57 тыс. руб.).

В результате проведенного анализа можно сделать вывод, что основными предпосылками для увеличения оборота недоброкачественных, фальсифицированных, контрафактных лекарственных средств являются:

1) наличие высокого уровня коррупции в государственном аппарате и руководящем звене;

2) нестабильность в экономической и социальной сферах страны;

3) большое количество аптек на рынке, что снижает возможность проведения постоянного контроля за их деятельностью;

4) несовершенство законодательства Российской Федерации, координирующего сферу оборота препаратов и сферу ответственности за правонарушения в обороте лекарственных средств;

5) рост списка лекарственных средств, что требует усиления контроля над регистрацией ЛС, так как в реестре находится более 15000 наименований и в нем можно обнаружить наличие препаратов с одинаковым названием;

6) использование ресурсов сети Интернет для распространения фальсифицированного продукта.

Государство предпринимает различные меры предупредительного и карательного характера для борьбы с фальсификатом на фармацевтическом рынке. Вышеизложенное подчеркивает необходимость введения новых норм, более детально регулирующих вопрос о фальсификации лекарственных средств, а также закрепления должного контроля и противодействия. Так, с 23.01. 2015 вступила в силу ст. 6.33, которая введена в КоАП РФ Федеральным законом от 31.12.2014 г. № 532-Ф3 «О внесении изменений в отдельные законодательные акты Российской Федерации в части противодействия обороту фальсифицированных, контрафактных, недоброкачественных и незарегистрированных лекарственных средств, медицинских изделий и фальсифицированных биологически активных добавок» [8]. Данная статья предусматривает административную ответственность за пра- вонарушения в сфере обращения фальсифицированных, контрафактных, незарегистрированных и недоброкачественных лекарственных средств, медицинских изделий и оборота фальсифицированных биологически активных добавок в виде штрафа:

- для граждан - в размере от 70 тыс. до 100 тыс. руб.,

- для должностных лиц - от 100 тыс. до 600 тыс. руб.,

- для индивидуальных предпринимателей от 100 тыс. до 600 тыс. руб. или административного приостановления деятельности на срок до девяноста суток;

- для юридических лиц - от 1 млн руб. до 5 млн руб. или административного приостановления деятельности на срок до девяноста суток.

Среди практических контрольных мер следует отметить, что с 01.01.2020 г. введено обязательное нанесение на упаковки лекарственных средств электронного идентификационного знака, содержащего всю информацию о лекарстве, - микрочипа, который при продаже сканируется на специальном оборудовании или через приложение на смартфоне, что позволит убедиться в подлинности товара. Благодаря такой защите цепочка «производитель - дистрибьютер - аптека» станет прозрачной. Возникают оправданные опасения, что это приведет к удорожанию лекарств, учитывая расходы на микрочипирование, особенно для лекарств нижнего ценового сегмента, и на считывающее оборудование.

\section{З А К ЛЮЧЕ НИЕ}

Подводя итоги, следует отметить, что в Российской Федерации проблема продажи, ввоза и реализации фальсифицированных лекарственных средств сейчас особенно актуальна и требует особого внимания. Непосредственное выявление причин, влекущих рост оборота недоброкачественных, фальсифицированных лекарственных средств, в дальнейшем позволит на более высоком уровне выработать комплекс определенных мер. Кроме того, ужесточение норм КоАП РФ в вопросах увеличения штрафа для физических лиц и предпринимателей, включая административный арест, а также угрозу увольнения должностного лица, является комплексом профилактических мер с целью предотвращения перехода мелкого административного правонарушения в уголовную плоскость на начальной стадии. Таким образом, государственная политика контроля оборота лекарственных средств - это необходимый элемент деятельности современного социального государства. Обеспечение качества, безопасности, эффек- 
тивности лекарственных средств является главной целью правового регулирования в данной сфере и выступает важным фактором укрепле- ния здоровья населения, представляющего национальный интерес Российской Федерации на долгосрочную перспективу.

\section{Е.А. Шумаева ${ }^{1}$ О.В. Гура ${ }^{2}$}

${ }^{1}$ ГОУ ВПО «Донецкий национальный технический университет», Донецк

${ }^{2}$ Республиканская служба лекарственных средств МЗ ДНР

\section{АНАЛИЗ ГОСУДАРСТВЕННОЙ ПОЛИТИКИ КОНТРОЛЯ ЗА ОБОРОТОМ ЛЕКАРСТВЕННЫХ СРЕДСТВ В РОССИЙСКОЙ ФЕДЕРАЦИИ}

В статье исследованы вопросы государственной политики контроля за оборотом лекарственных средств в Российской Федерации. Авторами проанализированы основные показатели, характеризующие состояние оборота лекарственных средств на фарма- цевтическом рынке страны, и выявлены предпосылки к возникновению нарушений в данной сфере.

Ключевые слова: государственная политика, фармацевтический рынок, оборот лекарственных средств, государственный контроль.

\section{E.A. Shumaeva ${ }^{1}$, O.V. Gura ${ }^{2}$}

${ }^{1}$ SEI HPE «Donetsk National Technical University», Donetsk ${ }^{2}$ Republic service of medicines of DPR Health Ministry

\section{ANALYSIS OF STATE SALE CONTROL POLICY OF MEDICINES IN THE RUSSIAN FEDERATION}

The article examines the issues of state sale control policy of medicines in the Russian Federation. The authors analyzed the main indicators that characterize the state of the sale of medicines in the pharmaceutical mar- ket of the country, and identified the prerequisites for the occurrence of violations in this area.

Key words: state policy, pharmaceutical market, sale of medicines, state control.

\section{ЛИТЕРАТУРА}

1. Аксенова-Сорохтей Ю.Н., Барановская Е.А. Инструменты государственного регулирования в сфере обращения лекарственных средств: правовой аспект. Молодой ученый. 2017; 8 (142): 215-221.

2. Маличенко В.С., Хабриев Р.У., Абашидзе А.Х. Роль развития системы регулирования обращения лекарственных средств в реализации права человека на наивысший достижимый уровень здоровья. Журнал зарубежного законодательства и сравнительного правоведения. 2016; 2: 16-22.

3. Федеральный закон Российской Федерации от 12.04 .2010 г. № 61-Ф3 «Об обращении лекарственных средств». URL: http://www.consultant.ru/document/ cons doc LAW 99350/

4. Антонова Т.А., Митюнова А.А. Правовое регулирование обращения лекарственных средств. Юридическая наука: традиции и инновации: сборник материалов международной научно-практической конференции студентов, магистрантов, аспирантов и преподавателей. 26-27 апреля 2019. Великий Новгород; 2019: 25-28.

5. Доклад об осуществлении государственного контроля (надзора) в сфере охраны здоровья граждан и об эффективности такого контроля (надзора) в 2018 г. URL: https://www. roszdravnadzor.ru/about/plans/ documents $/ 58302$

6. Доклад об осуществлении государственного контроля (надзора) в сфере охраны здоровья граждан и об эффективности такого контроля (надзора) в 2017 г. URL: https://www. roszdravnadzor.ru/about/plans/

\section{REFERENCES}

1. Aksenova-Sorokhtei Yu.N., Baranovskaya E.A. Tools of state regulation in the sphere of circulation of medicines: legal aspect. Molodoi uchenyi. 2017; 8 (142): 215-221 (in Russian).

2. Malichenko V.S., Khabriev R.U., Abashidze A.Kh. The role of the development of the system for regulating the circulation of medicines in the realization of the human right to the highest attainable standard of health. Zhurnal zarubezhnogo zakonodatel'stva i sravnitel'nogo pravovedeniya. 2016; 2: 16-22 (in Russian).

3. Federal'nyi zakon Rossiiskoi Federatsii ot 12.04.2010 g. № 61-FZ «Ob obrashchenii lekarstvennykh sredstv». Available at: http://www.consultant.ru/document/cons_doc LAW 99350/ (in Russian).

4. Antonova T.A., Mityunova A.A. Legal regulation of the circulation of medicines. Yuridicheskaya nauka: traditsii i innovatsii: sbornik materialov mezhdunarodnoi nauchno-prakticheskoi konferentsii studentov, magistrantov, aspirantov i prepodavatelei. 26-27 April 2019. Velikii Novgorod; 2019: 25-28 (in Russian).

5. Doklad ob osushchestvlenii gosudarstvennogo kontrolya (nadzora) v sfere okhrany zdorov'ya grazhdan i ob effektivnosti takogo kontrolya (nadzora) v 2018 g. Available at: https://www. roszdravnadzor.ru/about/plans/ documents/58302 (in Russian).

6. Doklad ob osushchestvlenii gosudarstvennogo kontrolya (nadzora) v sfere okhrany zdorov'ya grazhdan i ob effektivnosti takogo kontrolya (nadzora) v 2017 g. Available at: https://www. roszdravnadzor.ru/about/plans/ documents/50763 (in Russian). 
documents $/ 50763$

7. Федеральный закон Российской Федерации от 20.12.2001 г. № 195-Ф3 Кодекс Российской Федерации об административных правонарушениях. URL: http:// www.consultant.ru/document/ cons_doc_LAW_34661/073 006d2a2a599f5529cc8f48875a6a7625cf3b9/

8. Федеральный закон Российской Федерации от 31.12.2014 г. № 532-Ф3 «О внесении изменений в отдельные законодательные акты Российской Федерации в части противодействия обороту фальсифицированных, контрафактных, недоброкачественных и незарегистрированных лекарственных средств, медицинских изделий и фальсифицированных биологически активных добавок» URL: http://base.garant.ru/70833226 /\#ixzz 6GBcNqpLQ
7. Federal'nyi zakon Rossiiskoi Federatsii ot 20.12.2001 g. № 195-FZ Kodeks Rossiiskoi Federatsii ob administrativnykh pravonarusheniyakh: Available at: http://www.consultant. ru/document/ cons doc LAW_34661/073006d2a2a599f552 9cc8f48875a6a7625cf3b9/(in Russian).

8. Federal'nyi zakon Rossiiskoi Federatsii ot 31.12.2014 g. № $532-\mathrm{FZ}$ «O vnesenii izmenenii v otdel'nye zakonodatel'nye akty Rossiiskoi Federatsii v chasti protivodeistviya oborotu fal'sifitsirovannykh, kontrafaktnykh, nedobrokachestvennykh i nezaregistrirovannykh lekarstvennykh sredstv, meditsinskikh izdelii i fal'sifitsirovannykh biologicheski aktivnykh dobavok» Available at: http://base.garant. ru/70833226 /\#ixzz 6GBcNqpLQ (in Russian). 